\title{
Explosion of Excess Stock Ammunition, the Impact on the Health of the Civil Community and the Army.
}

\author{
Luan Nikollari' ${ }^{1}$, Adriana Bejleri ${ }^{1}$, Dorela Vasha ${ }^{1}$, Agron Dogjani ${ }^{1}$
}

\section{Abstract}

Albania, like all the former communist countries, has inherited in 50 years a large arsenal of weapons and ammunition stockpiles, as shells and projectiles of various calibers, which constituted a negative phenomenon and seriously jeopardized the lives of people and communities throughout the geography of their deployment. After the 1990s, the Albanian Armed Forces embarked on the path of transformation and integration of Albania into NATO. In this framework, the implementation of defense reforms aimed the reduction and modernization of the military. In this context, one of the transformation goals was the getting rid of the remaining excess ammunition that was being destroyed under the programs of the Ministry of Defense and partner countries and the role of the University Hospital of Trauma and the Military Hospital in Tirana, Albania. This paper aims to discuss the security threat that these stockpiles pose to our nation and the wiser region. It also explains how the excess munitions eliminating process was completed in Albania.

Keywords: excess stock ammunition, risks, elimination process, solutions

${ }^{*}$ Corresponding Author: Luan Nikollari

$\equiv$ E-mail: $\underline{\text { lnikolari@yahoo.it }}$

1University Hospital of Trauma, Tirana, Albania 


\section{Full text}

\section{Introduction}

Albania, like all the former communist countries, has inherited in 50 years a large arsenal of weapons and ammunition stockpiles, as shells and projectiles of various calibers, which constituted a negative phenomenon and seriously jeopardized the lives of people and communities throughout the geography of their deployment. After the 1990s, the Albanian Armed Forces embarked on the path of transformation and integration of Albania into NATO. In this framework, the implementation of defense reforms aimed the reduction and modernization of the military. In this context, one of the transformation goals was the getting rid of the remaining excess ammunition that was being destroyed under the programs of the Ministry of Defense and partner countries and the role of the University Hospital of Trauma and the Military Hospital in Tirana, Albania.

The legacy of the enormous stockpiling of military capabilities throughout the communist era has plagued Albania for more than two decades. These stockpiles pose a security threat to our nation and the wiser region.

From the public health point of view, the risks and threats were ranked as the following:

1. Natural risks:

a) Geological (earthquakes, rocks, landslides);

b) Hydrological (rivers and streams floods); c) Atmospheric (heavy snowfalls, snow storms, avalanches, wind storms, droughts);

d) Biophysics (epidemics, forest fires);

2. by human origin: floods from dams damages, technological disasters;

3. Potential ecological events due to a very large number of industrial facilities and installations of communist era now completely destroyed and abandoned.

However, among all these various risks and threats, a "hidden enemy" was not yet identified and discovered: risks and threats arising from the excess stocks of ammunition and explosives. (3)

\section{General Remarks}

The explosion of the ammunition collected for the demolition happened at the disposal site in a disestablished former military unit in Gërdec, on March 15, 2008 at 12:15 am, $10 \mathrm{~km}$ northwest of Tirana, near the Tirana-Durrës national highway, at a straightaway distance of about 3-4 km from the National Airport. (1)

The explosion, like an atomic mushroom, in a few minutes, created a huge detriment in the health of people directly or indirectly involved in the region and urged the immediate commitment and involvement of some disaster-related state agencies such as the Ministry of Defense, Ministry of Public Order, and Ministry of Health. This disaster caused 26 deaths and over 300 injured. More than $60 \%$ of the injured were treated in the Military Hospital (Picture 1). 

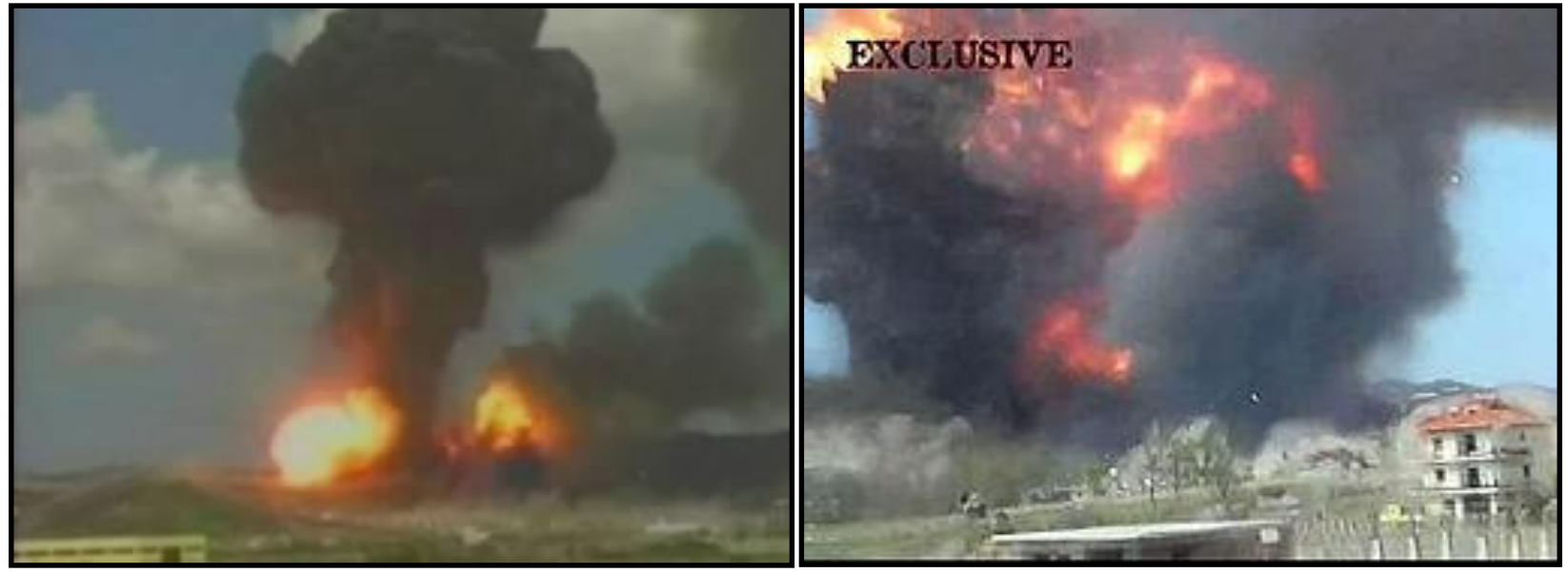

Picture 1: Some view of explosion in Gërdec on March 15, 2008, Vora-Tirana, Albania

The main purpose in this situation was the salvation of the lives of wounded and injured people, giving first aid, stabilizing and treating at the tertiary level.

The medical institution that hold the main burden and managed a large inflow of hurt people, because of its
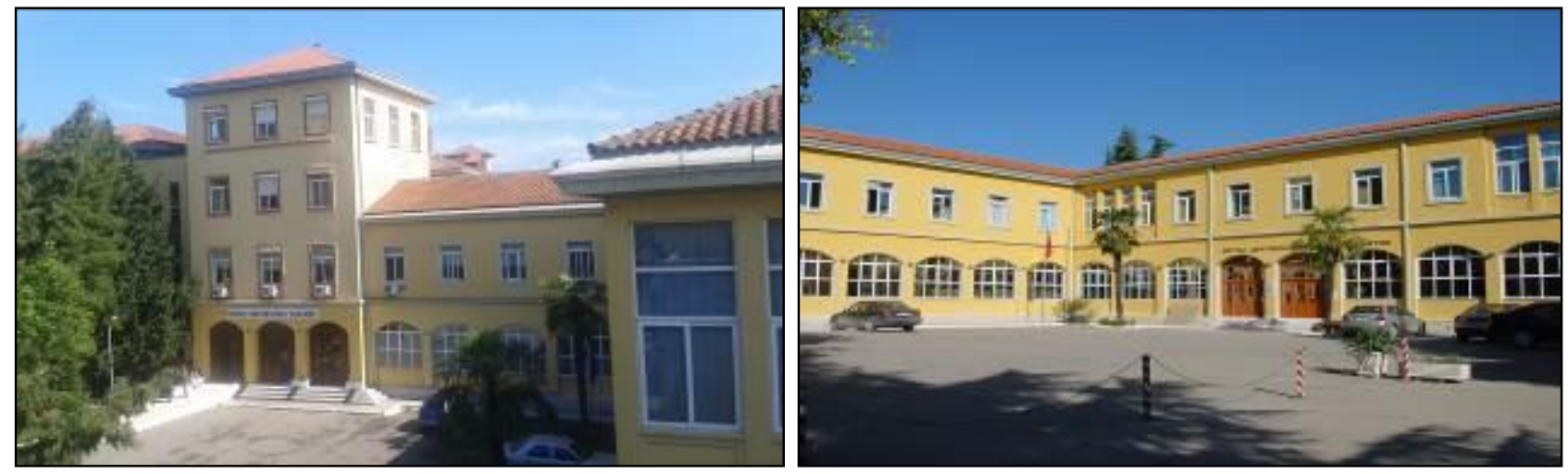

position as the closest medical facility, was the former Central Military Hospital $(\mathrm{CMH})$, today Trauma University Hospital and Military Hospital, as one of the most important medical institutions in country due to its tradition, experience created over the years activity as National Trauma Center (Picture 2).

Picture 2: University Hospital of Trauma \& Military Hospital Tirana, Albania

On March 15, the day of the event, even though it was the official holiday, in less than 25 minutes $100 \%$ of medical staff went at their workplaces without any official call or warning, but only 


\begin{tabular}{|c|c|c|c|c|c|c|c|c|}
\hline \multirow[t]{2}{*}{ No } & \multirow[t]{2}{*}{ Data } & \multicolumn{3}{|c|}{ Age } & \multicolumn{2}{|c|}{ Sex } & \multirow[t]{2}{*}{ Total } & \multirow[t]{2}{*}{$\%$} \\
\hline & & $0-14$ & $14-30$ & $>30$ & $\mathrm{M}$ & $\mathrm{F}$ & & \\
\hline 1 & Total Cases & 27 & 44 & 105 & 87 & 89 & 176 & 100 \\
\hline 2 & VLC & & & & & & 99 & 56.2 \\
\hline 3 & Fractures & & & & & & 20 & 11.3 \\
\hline 4 & $\begin{array}{l}\text { Commotions \& } \\
\text { Contusions }\end{array}$ & & & & & & 43 & 24.4 \\
\hline 5 & Armamputation & 1 & & & & 1 & 1 & 0.5 \\
\hline 6 & Different Burns & & & & & & 13 & 7.3 \\
\hline 7 & Total $(2+6)$ & & & & & & 176 & 100 \\
\hline 8 & Hospitalized & & & & & & 66 & 100 \\
\hline 9 & Evacuated abroad & \multicolumn{5}{|c|}{ Greece } & 6 & $9 \%$ \\
\hline & & \multicolumn{5}{|c|}{ Italy } & 4 & $6 \%$ \\
\hline & & \multicolumn{5}{|c|}{ Turkey } & 1 & $1 \%$ \\
\hline & & \multicolumn{5}{|c|}{ Total } & 11 & $16.6 \%$ \\
\hline
\end{tabular}

Table 1: Statistical Data, Ammunition Explosion in Gerdec - March 2008

Over $98 \%$ of those injured treated in Emergency Ward had incision, crush wounds at the head, face and extremities, limb fractures, body and head contusions, burns etc (Picture 3).
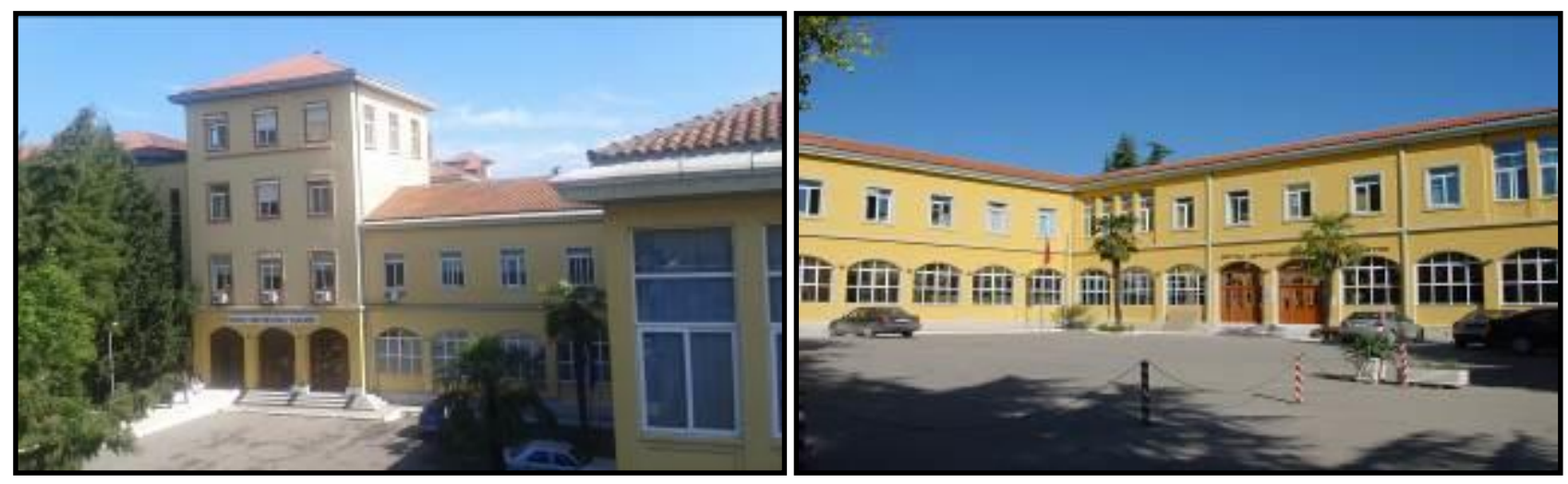

Picture 3: Views of traumatized from the explosion presented to the Emergency of the Military Hospital

Emergency medical staff and all other hospital departments, with unmatched dedication, professionalism, humanism and solidarity, elaborated and stabilized all the injured. The private "American Hospital" was also directly committed in providing first aid and hospitalizing the serious cases. This was highly 
appreciated by all the top authorities of the country and foreigners.

Six of the most seriously injured hospitalized in Military Hospital, were transported to Thessaloniki and Ioannina Hospitals in Greece and four others to Italy. It is also worth mentioning and appreciated the support and helps coming from France, USA, Germany and Greece with medical supplies and equipment, and the assistance and solidarity of neighboring and other countries like, Italy, Turkey, Greece, FYROM, Kosovo and the involvement of the diplomatic corps and military attaches to this humanitarian operation.

The Preventive Medicine Corps, part of the Military Medical Institute, provided the health insurance of the military troops engaged on search and rescue and consequences relieving operations at the site of the explosion. For this purpose, the Health Service of the Commando Forces and the Rapid Reaction Brigade (Land Force) established a field health center close to the explosion area with medical personnel, evacuation tools etc (Picture 4).

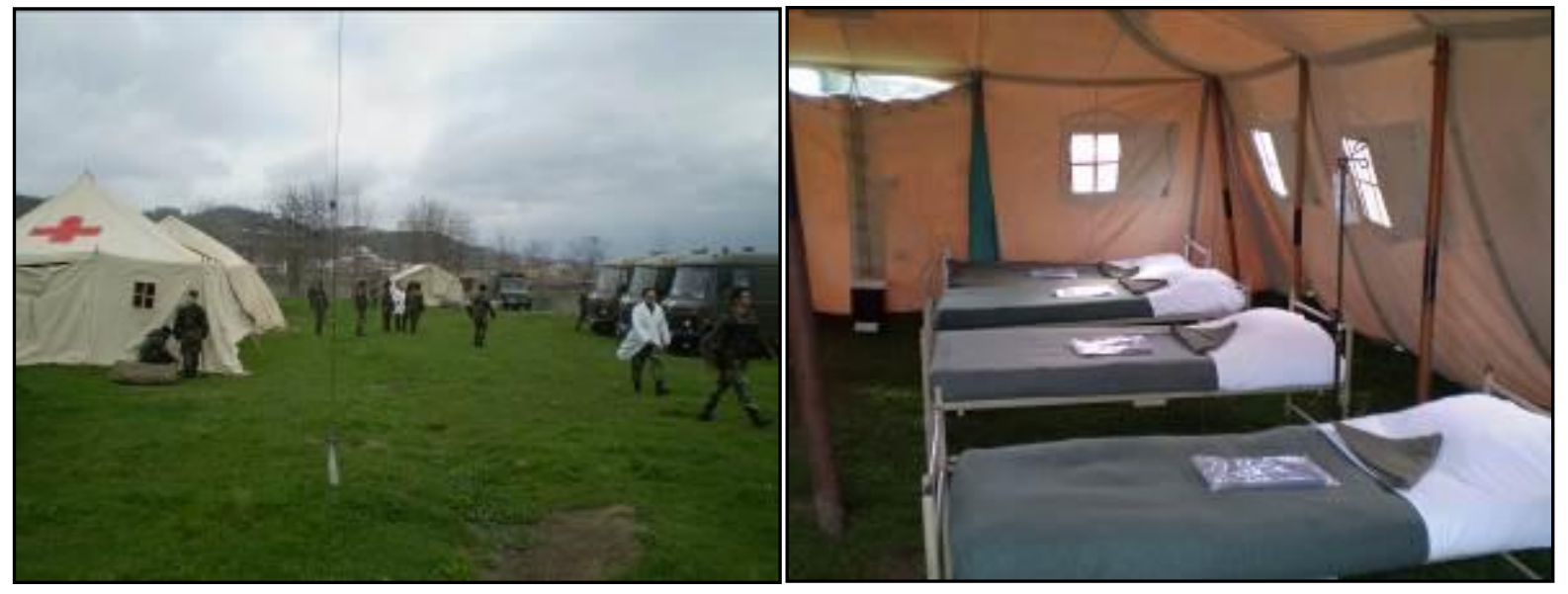

Picture 4: Medical Facility Role 1 in field

For the health insurance of the military troops participating in the operation, in addition of the Operational Center for providing troops support, it were established and engaged even Field Health Centers manned with high and medium professional level personnel, with 10 beds, ambulances as well as additional supporting personnel and medical evacuation means and capabilities. This entire staff coordinates perfectly with each other for health support operations. Considerable military forces were directly committed in searching and clearing operations at the disaster area, almost right away after explosion. These committed forces were closely and directly supported by medical personnel for providing their first aid to the field. The military troops engaged on the cleaning operations' area were provided with dust masks protection, handgrips for the protection of hands from hurts of metal scraping wastes, explosive shell pieces, etc. Hygiene and sanitation nods were also 
set up in support of all military forces committed on operations in field (Picture 5).
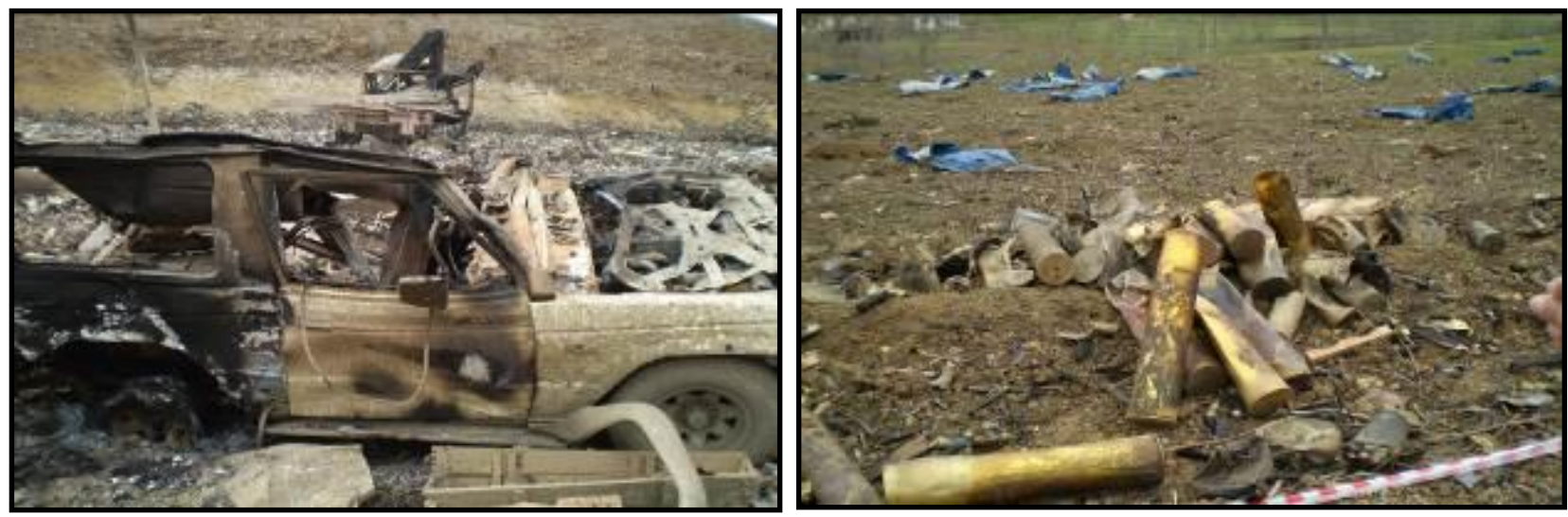

Picture 5: The scene after the exploded large caliber, shells scattered after the explosion

After Armed Forces' medical Service intervention, it was the Forensic Medicine Institute that provided legal experts and necessary logistic stuff (plastic bags) for the for the removal of dead bodies and body wastes found and further on, for the transport of corpses.

All dead animals and poultries found within and around the explosion area were disinfected with hypochlorite and buried in deeply grounded landfills. For this purpose Albanian Armed Forces veterinary staff was involved in identification of animal and poultries dead bodies, in coordination with specialized stuff and counterparts of country's other veterinary agencies to prevent the spread out of infections and epidemics.

All military forces and other personnel that participated in the operation applied prophylactic vaccination with a dose of
Rapel with anti-tetanus Immunoglobulin $1 \mathrm{ml}$ for 600 persons.

An additional health problem was the dead animals and poultries. In the disaster area some 233 (19 cattle, 4 small livestock, 3 pigs, 4 equines and 203 birds) dead animals and poultries were found, disinfected and buried.

\section{Lessons learned}

The bitter experience stemmed from this abovementioned huge explosion, has been subject of a careful consideration, in order to identify the problems, shortages and responsibilities.

First of them was a re-assessment of the potential risks and threats that can face the military and civil community from the excess stock ammunition, but not only.

Another problem that needed urgent solution was the training and early 
preparation of military forces, especially military medical personnel, for effective management of major human disasters. In this context, it has been discussed installing better utilization human and medical resources. In this framework, creating and establishing the necessary medical logistic reserve, especially on medicines and medical supplies at the depot and pharmacies network has been one of the most urgent General Staff's decision.

Effective and better coordination between domestic civil-military medical services capabilities with foreign assistance and support has been considered one of the main measure in order to speed up the process.

Last, but not the least, the Health Directory in the General Staff has established or updated all the medical Standard Operation Procedures (SOP) for any similar situation in the future, in order these kind of situations be effectively managed.

Based on the abovementioned lessons learned, all the difficulties and problems have been considered and solutions have been reviewed. Any plan, any program at any site related to the elimination of the excessive stockpiles of munitions have been vested with disciplined medical measures. Medical teams that were equipped with all the necessary techniques were present from the beginning to the end of the process. The teams that were in charge of the elimination process have been certified not only from the professional point of view but from the medical point of view as well in order to successfully face even the smallest health situation. At any case, the military hospital has been devoted a ready medical team on $24 \mathrm{~h}$ bases in order to respond in time to any unexpected situation.

Nowadays Albania has completed the excess munitions elimination process, but very strict rules and instructions for the management readiness and reserve munitions have been determined. Medical training is definitely an integrated part of professional training.

This demilitarization process was accomplished using different methodologies, in order not to avoid any massive ammunition consolidation. The primary emphasis was placed on the industrial dismantling of munitions at three distant military factories: Mjekës, Gramsh and Poliçan. When industrial demilitarization was impossible due to technical and safety reasons, we carried out open detonations at 11 demolition ranges throughout the country, with all detonation sites approved by Parliament. A much smaller amount of munitions were sold and exported, generating much needed revenue to help fund the demilitarization effort. As part of the demilitarization process we have been able to close 23 legacy munitions storage locations. It has been decided an extremely rigorous process of sitecleaning, checking and certification prior to declaring any site free of munitions or explosive material. At any case rigorous standards has been decided related to oversight and certification role while in the supervision, training, accreditation and certification processes in order to ensure safe operations. 
At the end of the year 2016, more than 100.000 tons of munitions have been eliminated, which equates to approximately 450 million rounds of various calibers. Due to the above mentioned measures, not even the smallest accident occurred. All the process has been completed in a safe and secure environment.

\section{References}

1. Powell, Mike: "The New York Times - Breaking News, World News \& Multimedia". International Herald Tribune. Retrieved 2017-01-08.

2. Powell, Mike: "Death toll from Albanian dump blast climbs". Usatoday.com. 2008-03-21. Retrieved 2017-01-08.
3. Dogjani, Agron. (2010).

"Management of Explosions and Blast Injuries after Gerdec Tragedy". 10.1007/s00068-010-8888-z.

4. Kakarriqi E,: “General background of Potential Disaster Risks in Albania", 3rd Public Health Fund of the Institute of Public Health, Conference of Institute of Public Health , 11-13.2.2006 Tirana, Albania.

5. Law No. 72/2015 "For the approval of the Military Strategy of the Republic of Albania", 2015, pg.33.

6. Pierre Cobinet, Tom Van Beneden, "Small Arms Survey - The regional Approach to Stockpile Reduction", April 2012.

7. "Ushtria" - Albanian Defence Newspaper "NATO: The unique case of Albania for the munitions annihilation", October 2012 